\title{
HISTORIA MEXICANA \\ CUMPLE 70 AÑOS
}

\author{
Josefina Zoraida Vázquez \\ El Colegio de México
}

\begin{abstract}
1 desaparecer los miembros de la "vieja guardia" a quienes A tocó atestiguar la aparición de Historia Mexicana, soy la que más tiempo ha estado en contacto con la revista, tanto que pude ver el original cartel que anunciaba su aparición. Fue cuando cursaba el segundo año de la carrera en Filosofía y Letras, por entonces en el edificio de Mascarones, en San Cosme, pues la Ciudad Universitaria estaba en construcción. El edificio, un inmueble virreinal tenía la ventaja de estar bien comunicado, tanto por camiones como por tranvías que eran un medio cómodo de transporte en aquella ciudad que para los términos de hoy era pequeñísima. Casi todos los alumnos y profesores llegábamos en tranvía, la excepción era un par de profesores y una docena de alumnos que lo hacían en auto y un profesor que llegaba en moto. Una de mis compañeras y yo, al salir de clases a las 8 de la noche, tomábamos el tranvía en la esquina, frente a la puerta de la Facultad. En casi todas las esquinas de calles y avenidas con mucho tráfico, había unos tableros de madera en los que se anunciaban las obras de teatro, los programas de cine, deportes, corridas de toros y propaganda política impresas en hojas largas de papel que se pegaban con engrudo. En espera
\end{abstract}


del tranvía, las personas leíamos y releíamos esos anuncios. Recuerdo bien que una noche me llamó la atención una novedad: un cartel anunciaba la próxima aparición del primer número de Historia Mexicana. Lo comenté con mi compañera, quien le restó importancia porque nosotras cursábamos historia universal. En mi caso, la curiosidad me hizo tomar nota y obtenerla en cuanto estuvo disponible. Desde luego ese número era totalmente distinto de nuestra revista actual. En primer lugar, era más de difusión, con artículos breves y casi sin citas. La presentación era semejante, con la portada verde seco y sus 160 páginas, sin relación con los rechonchos números de hoy que han llegado a duplicar ese tamaño, con artículos concienzudos, producto de investigación, sin duda una muestra del profesionalismo alcanzado por nuestra disciplina, proceso que puede seguirse a lo largo de sus números. Mi padre le echó un vistazo a la revista y le llamó la atención que el Consejo de Redacción lo constituyeran intelectuales muy conocidos.

Desde niña, me encantaban las revistas, tanto que revisaba las que leía mi padre y devoraba las páginas del Billiken, compañero de mi infancia. En sus páginas aprendí de historia, geografía, animales y flora de Argentina, país donde se publicaba, por lo que llegué a saber más de ese país que del mío, aunque también me despertó interés en todas las ramas de la geografía y, desde luego, en la historia. En sus notas históricas me sorprendió que no se mencionaran las crueldades de los conquistadores ni la violencia de la independencia, tan subrayadas en mis textos escolares de historia de México, que siempre se referían a guerras y cambios de gobierno. Historia Mexicana me gustó por la ponderación de sus artículos, característica que más tarde me enteraría había sido uno de los principios que don Daniel Cosío Villegas quiso imprimirle a la revista, abriéndola a todas las corrientes y eliminando "prejuicios y banderías", al tiempo de publicar "trabajos sobre historia mexicana de mexicanos y extranjeros". De esa manera, la lectura de Historia Mexicana contribuyó a completar 
mi formación y despertó mi interés en la historia de mi país, que habían envenenado algunas versiones de indigenistas e hispanistas, como las de doña Eulalia Guzmán, Rubén García o el padre Mariano Cuevas, amén de mis libros oficiales de texto. Desde el principio atrajeron mi atención los llamativos títulos que elegía don Daniel, como "Magdalena, la ingrávida”, “YYa viene la bola!”, “¿Dónde está el villano?”, “Los frutos del golpe”.

Don Daniel apunta en sus notas para la celebración de los 10 años de Historia Mexicana, que siempre pensó que todo centro de investigación debía tener una revista que lo representara, aunque Luis González atribuye al maestro José Miranda la idea de fundar una revista, orgulloso de la formación de los discípulos de historia, pensando que esto les permitiría divulgar los resultados de sus investigaciones, y afirma que a don Daniel le gustó la idea. ${ }^{1}$ Lo cierto es que los objetivos de los dos eran totalmente diferentes: si Miranda quería resolver el problema de un pequeño grupo de jóvenes que seguramente encontrarían acomodo, a don Daniel le interesaba más que los historiadores de provincia publicaran artículos como medio para ampliar los horizontes académicos del país y, al mismo tiempo, llegar a un público general, siempre interesado por la historia del país.

Don Daniel tenía experiencia editorial como fundador y director del Fondo de Cultura Económica y de El Trimestre Económico, pero para publicar la revista requería recursos, dada las escaseces de esos tiempos. Para sus grandes empresas don Daniel había desarrollado un método muy bien armado. Gracias a la amistad con muchos altos funcionarios, siempre lo auxiliaba alguno que se prestaba a convocar a una junta de banqueros y empresarios importantes, y contaba con un simpatizante, el general Aarón Sáenz, quien también era empresario y quien apenas terminaba la presentación del proyecto, se apresuraba a ofrecer

1 Cosío Villegas, “Un poco de historia” (100), 1976), pp. 505-529; GonZÁLEZ, "La pasión del nido” (100), 1976, pp. 530-598. 
una cantidad grande, de manera que los otros, más importantes que él, la igualaran o aumentaran. Para 1950 ese método se había dejado de lado pues la gran aventura de don Daniel a finales de los años cuarenta, el Seminario de Historia Moderna de México para investigar en profundidad la historia de la Reforma, la Restauración de la República y la dictadura porfirista, había logrado que la Fundación Rockefeller lo financiara, como también al proyecto de enviar graduados mexicanos becados para especializarse en materias que no tenían las instituciones de educación superior mexicanas, a universidades de Estados Unidos o de Europa. Don Daniel traía ya entre ceja y ceja fundar una serie de centros de investigación en estudios internacionales, económicos, demográficos, así como revivir la docencia en historia y sociología.

Para la revista, don Daniel consiguió aportaciones de Alberto Misrachi, Nacional Financiera, Banco de México, Virgilio M. Galindo, Compañía Fundidora de Fierro y Acero de Monterrey, Financiera Nacional Azucarera, Banco Nacional de México, Carlos Trouyet, Banco Agrícola y Ganadero de Toluca, Altos Hornos de México y Raúl Baillères, lo que permitió financiar los primeros números de la revista, hasta que El Colegio se institucionalizó y pudo absorber el gasto.

Historia Mexicana apareció en septiembre de 1951; sus primeras 6 páginas eran de publicidad de la Librería Porrúa, Banco de México, Petróleos Mexicanos, más un anuncio de las publicaciones de El Colegio y, desde el cuarto número, también un anuncio de la Cervecería Moctezuma que había adquirido el grupo Baillères. Total, en septiembre de 1951, el Centro de Estudios Históricos, el primero en fundarse, al fin contaba con una revista, curiosamente cuando se había suspendido la docencia. En sus primeros años la revista estuvo a cargo del propio Cosío, con el apoyo en la corrección de textos de Antonio Alatorre.

Uno de los trabajos que yo había presentado en el Seminario de Historiografía Mexicana, de don Juan Ortega y Medina, a 
fines de 1959, sobre Manuel Payno, al maestro le pareció que era publicable y se lo llevó a don Daniel. El artículo tuvo suerte y poco después, apareció en el número 29 (jul.-sep. 1960), con el título "La historiografía romántica en México". Es posible que el artículo o los comentarios de Ortega al presentarle el trabajo fueran la razón por la que don Daniel, en aquel entonces en busca de candidatos para el Seminario de Historia Contemporánea, decidiera probarme, pues ese verano de 1960, cuando estaba con una beca de la oes en la Universidad de Cuyo, en la Argentina, recibí la invitación. Desde luego acepté y el 1ํ de noviembre de 1960 me incorporé a El Colegio, todavía en un viejo edificio frente a la Plaza Río de Janeiro, poco antes de que se trasladara al pequeño edificio de Guanajuato 125, primera casa propia de la institución. Por tanto, me tocó asistir a la celebración de los 10 años de Historia Mexicana en el otoño de 1961. En la biblioteca del pequeño pero flamante edificio, se organizó un coctel, "con tequila para los extranjeros y whisky para los mexicanos", y se invitó a funcionarios de fundaciones e instituciones académicas y profesores. El coctel estuvo muy concurrido y resultó realmente agradable. Don Daniel aprovechó para sondear posibles becarios para ser enviados a especializarse en el extranjero y profesores para la maestría en historia, que estaba a punto de reiniciarse. Las invitaciones especificaban el horario de 7 a 10 p. m., pero a esa hora nadie parecía dispuesto a despedirse, por lo que don Daniel ordenó que se apagara y prendiera la luz en señal de fin de fiesta, no sin antes ofrecer un brindis que realmente nos conmovió por la emoción con que don Daniel gritó, “'Señores, por El Colegio de México!, ipor El Colegio de México y por El Colegio de México!”.

A dos años de mi entrada en la institución, en 1962, don Daniel me ofreció la beca Rockefeller para especializarme en historia de Estados Unidos en la Universidad de Harvard. Aunque apenas había tiempo para conseguir la beca y la admisión a la Universidad, Cosío logró las dos, al presentar la importancia 
del caso, ya que no había un solo especialista en historia de Estados Unidos en Latinoamérica. Así, pude iniciar mis cursos en el otoño de 1962. Los dos años fueron de intenso trabajo, pero con buenos profesores, condiciones inmejorables y la maravillosa Biblioteca Widener. La experiencia fue dura, pero privilegiada. Satisfecha, regresé en el otoño de 1964 a un Colegio diferente. Don Daniel había dejado la presidencia de la institución después de sufrir un infarto. La nueva presidencia y la dirección del CEH pusieron en entredicho el contrato firmado con la Rockefeller, por el cual tanto yo como la institución nos comprometíamos a que regresaría y me integraría a El Colegio por lo menos durante dos años como profesora investigadora. Desde luego la Fundación exigió el cumplimiento del acuerdo y empecé a dar clases de historia de Estados Unidos en los centros de Estudios Internacionales y de Estudios Históricos, con algún éxito, y me pusieron a cargo de Historia Mexicana. El trabajo de la revista por entonces, igual que ahora, era engorroso, pues no tenía secretaria ni ayuda alguna y requería que personalmente se llevaran a la imprenta los artículos e ir a recoger después galeras y planas y devolverlas corregidas; tarea muy absorbente, pero grata, para quienes nacimos entre galeras y planas de imprenta. Por entonces se preparaban unos números especiales para celebrar los 25 años de El Colegio de México, y dado que la historia era el aspecto en que la institución había destacado más, se pensó adecuado hacer un recuento de las contribuciones historiográficas de México en esos 25 años de vida de El Colegio de México. Así que, además de preparar dos números de la revista, dediqué gran parte de mi tiempo a reunir ese material. Para empezar, se hizo una larga lista de historiadores de diversas ramas de la profesión para entrar en contacto con ellos e invitarlos a elaborar artículos que revisaran lo producido en ese periodo y comentarlo. En ese aspecto conté con el invaluable auxilio de Luis González y de don Juan Ortega y Medina. Después localicé a los posibles colaboradores, los visité y los invité. Fue una tarea 
desgastante, porque había que recordarles el compromiso para que cumplieran con los plazos y sustituir a los incumplidos. No obstante, logré reunir todo el material, justo en el momento en que la directora del Centro, María del Carmen Velázquez, me comunicó que había decidido que Jorge Alberto Manrique se encargara de la revista. De manera que después de tanto trabajo, no me tocó publicarlo. El material apareció en los números 58-59 y 60 de Historia Mexicana y, además, se publicó en un volumen aparte bajo el título de Veinticinco años de investigación histórica en México. Los autores hicieron bibliografías selectivas, comentadas, sobre los diversos campos de la historia, con libertad en cuanto a los criterios de selección y organización de sus materiales. El volumen especial resultó un grueso tomo con una advertencia de Manrique, en la que olvidó mencionar mi aportación.

Poco después salió a concurso una plaza del Instituto de Investigaciones Estéticas de la UNAM y Manrique, experto en historia del arte, decidió concursar; desde luego, fue elegido, por lo que lamentamos perderlo. Para ese momento, Luis González había asumido la dirección del Centro y eligió a Enrique Florescano para hacerse cargo de Historia Mexicana, a partir del número 79 (ene.-mar. 1971). Hasta entonces la política de la revista había sido no dar crédito al trabajo de edición de la revista, de manera que ni Luis González, ni Manrique ni yo tuvimos crédito por hacerlo y Florescano fue el primero en aparecer como director y, a partir del siguiente número, Héctor Aguilar Camín figuró como secretario de redacción. Su colaboración fue fructífera y duró hasta el número 92 (abr.-jun. 1974), con varios números monográficos que empezaron a pasar por alto el límite de páginas.

En el ínterin, Enrique Florescano fue nombrado director nada menos que del Instituto Nacional de Antropología e Historia, una institución enorme y compleja, lo que no obstó para que mantuviera la dirección de Historia Mexicana hasta que 
Luis González renunció a la dirección del CEH en 1973 y fui nombrada para sustituirlo. $\mathrm{Al}$ agradecer el nombramiento, puse como condición que la revista regresara al Centro. El presidente de El Colegio, Víctor Urquidi, consideró justa la petición y él directamente le comunicó a Florescano la decisión.

A partir del número 93 (jul.-sep. 1974) se hizo cargo de la revista Bernardo García, quien apareció sólo como redactor del número 94 hasta el 101 (oct.-dic. 1974-jul.-sep. 1976), con Anne Staples como secretaria de redacción, tarea que desempeñaría Victoria Lerner del 102 al 104 (oct.-dic. 1976-abr.-jun. 1977). Bernardo estuvo a cargo de Historia Mexicana hasta el número 105 (jul.-sep. 1977), con el profesionalismo y dedicación con el que siempre cumplía todas las tareas, y aunque disfrutaba editar la revista, en 1982 decidió dejarla para dedicarse a preparar su tesis doctoral para publicación. Lo sucedió como redactor Luis Muro, de los números 126-144 (oct.-dic. 1982-abr.-jun. 1987). A la muerte de Luis Muro, Bertha Ulloa, directora del CEH en ese entonces, entregó la revista a Alfonso Martínez Rosales, quien fue director, junto con Carlos Macías como secretario de redacción, del número 145 (jul.-sep.- 1987) al 151 (ene.-mar. 1989).

$\mathrm{Al}$ asumir Alicia Hernández la dirección del $\mathrm{CEH}$, nombró directora de la revista a Clara E. Lida, quien la editaría del número 152 al 156 (abr.-jun. 1989-abr.-jun. 1990), con Dorothy Tanck como redactora, y del 157 al 161 (jul.-sep. 1990-jul.-sep. 1991) con Manuel Miño como redactor. Clara E. Lida introdujo cambios importantes a Historia Mexicana: estableció un Consejo Asesor con parte de los profesores del CEH y colegas de otras instituciones (Carlos Sempat Assadourian, Jan Bazant, David A. Brading, Marcello Carmagnani, Pedro Carrasco, Bernardo García Martínez, Luis González y González, Moisés González Navarro, Alicia Hernández Chávez, Friedrich Katz, Elías Trabulse, Berta Ulloa, Josefina Zoraida Vázquez y John Womack). El viejo Consejo de Redacción que formaban todos los profesores de Centro pasó a ser Comité Interno, con los profesores que 
no integraban el Asesor: Solange Alberro, Lilia Díaz, Romana Falcón, Pilar Gonzalbo Aizpuru, Virginia González Claverán, Carlos Marichal, Alfonso Martínez Rosales, Manuel Miño Grijalva, Francisco Xavier Noguez, Anne Staples y Dorothy Tanck de Estrada. Estos consejos han permanecido, aunque han variado con la entrada y salida de profesores por retiro o muerte.

No recuerdo por qué Clara Lida decidió dejar la dirección de la revista, pero Alicia Hernández me nombró directora de Historia Mexicana del número 162 al 168 (oct.-dic. 1991-abr.-jun. 1993). En ese entonces, recibí la invitación para pasar un año en el Center for Advanced Studies in the Behavioral Sciences en Stanford, California. Desde luego me apresté a aprovecharlo para disfrutar de un sabático completo, además de que la beca daba facilidades especiales para continuar con mis investigaciones de historia diplomática, con la única obligación de tomar el lunch con los otros becarios, participar en reuniones especiales y presentar una conferencia sobre el tema de investigación. Las condiciones permitían dirigir la revista porque ya se contaba con medios electrónicos y había dejado dos números preparados, pero apenas llegada al Center, recibí la llamada de Alicia Hernández para anunciarme que había nombrado a Solange Alberro para sustituirme, aunque recibí crédito por los números preparados. El último número que apareció bajo mi dirección fue el único que superó el número de páginas (unas 640 por volumen), pero yo no lo había preparado. Manuel Miño, que aparecía como redactor, figuró entonces como coordinador y en la introducción explicó que el material era el producto de una iniciativa que habían tenido Clara E. Lida y él un año antes, de invitar a un grupo de historiadores distinguidos a preparar artículos sobre "México e Hispanoamérica. Una reflexión historiográfica en el Quinto Centenario".

Solange Alberro dirigió Historia Mexicana del número 169 (jul.-sep. 1993) al 206 (oct.-dic. 2002) y tuvo la suerte de contar con Beatriz Morán Gortari como redactora, nombrada 
de manera permanente, lo que permitió dar continuidad a las tareas, además de ser un auxilio importante para los directores. Solange introdujo modificaciones a los Consejos para que uno fuera Internacional ${ }^{2}$ y otro Nacional, con miembros destacados del gremio. El Comité Interno, constituido por profesores del Centro, ha tenido variaciones de acuerdo a los retiros y nombramientos de profesores.

La doctora Alberro mantuvo el discreto tamaño tradicional de la revista y sólo rebasó la paginación el número 200, conmemorativo de los 50 años de Historia Mexicana. Al sucederla Óscar Mazín, del número 207 al 258 (ene-mar. 2003 a oct-dic. 2015), se tomó la decisión de extender el límite de paginación y los volúmenes engrosaron hasta llegar a duplicar la paginación original. Eso impidió que los que habíamos empastado los volúmenes, pudiéramos continuar haciéndolo. En tiempos de carencias valdría la pena reconsiderar fijar el límite de páginas, sin que valga la excusa de que llega un número creciente de artículos (véase la tabla de la sección Numeralia).

La revista había alcanzado gran prestigio al ofrecer artículos originales producto de investigación y un número creciente de reseñas para mantener al lector informado de las publicaciones, algo que aplaudiría don Daniel, al tiempo que lamentaría que la revista no promoviera que los libros del Centro fueran comentados, así como él enviaba galeras o planas a estudiosos mexicanos o extranjeros que podían criticarlos, de manera que,

${ }^{2}$ Linda Arnold de Virginia Tech; David A. Brading, University of Cambridge; Louise Burkhart, University of Albany; François Chevalier, Université de Paris I-Sorbonne; Serge Gruzinski, École des Hautes Études en Sciences Sociales; Charles Hale, University of Iowa; John Coatsworth, Harvard University; John Elliot, University of Oxford; Nancy Farris, University of Pennsylvania; Manuela Cristina García Bernal, Universidad de Sevilla; Friedrich Katz, University of Chicago; Allan Knight, University of Oxford; Herbert J. Nickel, University of Bayreuth; Arij Ouweneel, Centrum voor Studie en Domentatie van Latijns Amerika; Mariano Peset, Universidad de Valencia; Horst Pietschmann, Universidad de Hamburgo. 
al salir publicados, los esperaban varias crónicas. Creo que esa práctica podría adaptarse de alguna forma, para que excelentes publicaciones de El Colegio no quedaran sin reseñarse.

A Óscar Mazín lo sucedió Pablo Yankelevich, quien editó los números 259-276 (ene.-mar. 2016-abr.-jun. 2020) y, como cada director, le imprimió su sello particular. Al ser nombrado director del Centro, eligió al doctor Rafael Rojas como director de Historia Mexicana, con Beatriz Morán Gortari como redactora y Frida Martínez León como asistente de redacción.

Al hacer un análisis somero de los volúmenes desde la última vez que la reseñamos, se desprenden algunas observaciones. El rubro minoritario, sólo seis artículos, continúa siendo el de las culturas prehispánicas, seguramente porque hay dos revistas dedicadas a las culturas nahua y maya. El periodo colonial continúa teniendo importancia, aunque parece haberse inclinado al siglo XviII. Los artículos dedicados al siglo XIX, que se multiplicaron por el impulso que le daría el Seminario de Historia Moderna, organizado y dirigido por don Daniel Cosío, llegaron a 147, concentrados en la segunda mitad del siglo. Aparecieron artículos sobre la independencia, pero sin ocuparse casi del periodo de transición y pérdidas, 1824-1854. También aumentó el número de artículos dedicados al siglo xx que llegaron a 336. La temática de los siglos XIX y xx fue mayoritariamente historia política, aunque aparecieron buenas contribuciones de historia económica, social y cultural, amén de algunos intentos comparativos. En los volúmenes revisados aumentaron los estudios de historiografía, sin que llegara a cumplirse el foro de inquietudes filosóficas que se debatían en las décadas de los cuarenta y los cincuenta, como los publicado por don José Gaos, "Notas sobre historiografía" $(36,1960)$, en parte seguramente porque las inquietudes filosóficas que habían agitado los ánimos entonces habían pasado, pero también porque los publicados analizaban sólo la producción histórica mexicana o la obra de un historiador mexicano. La historia diplomática apenas mereció 4 
artículos, probablemente porque prefieren publicarlos en Foro Internacional. En cambio, han aparecido buenas contribuciones de historia jurídica y la historia económica ha cobrado espacio y llegó a 26 artículos. Algo que es una lástima es que la revisión de archivos haya perdido el lugar importante que ocupaba en periodos anteriores, aunque todavía hubo 33 revisiones. El aspecto que realmente ha aumentado en forma considerable es el de las reseñas en estos volúmenes, ya que llegaron a 861, aunque no siempre con el espíritu crítico que Cosío quería inyectarle a la revista, y menos, "la capacidad de recibirla con buen espíritu". Aunque hay debates que parecen recordar las reseñas de los primeros tiempos, en general no alcanzan las dimensiones que llegaron a tener algunas y es una lástima que desaparecieran las reseñas múltiples que daban noticia de las aportaciones de mexicanistas de diversos países.

En los 70 años de Historia Mexicana, la revista ha reflejado los cambios y la profesionalización de la historia. Tal vez perdió el gusto de los tiempos iniciales por difundir la historia con textos cortos y más fluidos que los largos artículos que aparecen ahora, pero en cambio, la revista ha pasado a desempeñar un importante papel pedagógico al entregar material que complementa las lecturas de los estudiantes y proveer elementos para las listas de bibliografía preparadas por los profesores.

Sin empacho creo que podemos mostrarnos satisfechos, aunque nos vendrá bien pensar en plantearnos aspectos que valgan la pena ser reconsiderados, pues siempre es buen momento para reflexionar sobre el futuro de nuestra revista. 